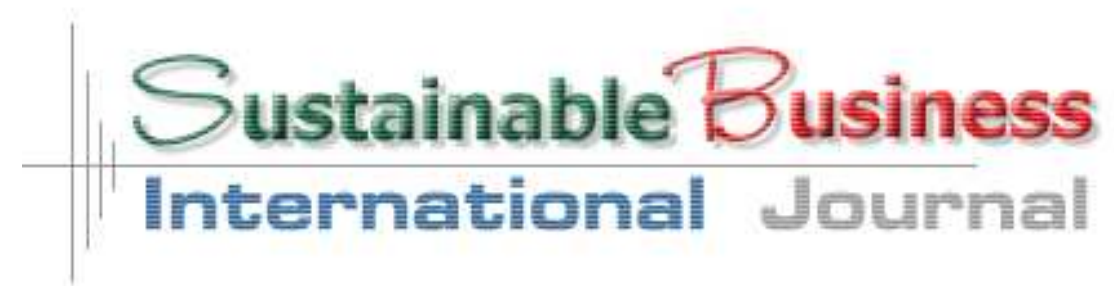

MAIO DE 2012-ISSN 1807-5908

\title{
UTILIZAÇÃO DE CAPSULAS PARA O TRANSPORTE DE CARGAS POR DUTOS
}

\author{
Aurelio Lamare Soares Murta, DSc - UFF ${ }^{1}$ \\ Maria Cristina Fogliatti De Sinay, DSc - IME ${ }^{2}$
}

\section{Resumo}

Com a saturação do sistema rodoviário e o tráfego crescente no transporte de cargas e passageiros, muitas das estradas brasileiras já se encontram permanentemente congestionadas, o que piora ainda mais a situação. A idéia de construir mais estradas deixou de ser uma prioridade na maioria das vezes por razões fiscais e ambientais. Pesquisas estão sendo desenvolvidas a fim de se aumentar a capacidade da infraestrutura existente e ao mesmo tempo, tem-se dado importância ao estudo de novos sistemas de transporte. A utilização de dutos para o transporte de alguns tipos de cargas, antes transportadas por caminhões, tem mostrado eficiência e segurança nestes deslocamentos. Este modo de transporte já é experimentado em vários países há muitos anos, e no que diz respeito a cargas líquidas ou pastosas, este meio sempre apresentou maior rendimento e segurança do que os demais concorrentes. Uma nova idéia seria a de usar cápsulas para transportar cargas sólidas por meio de dutos, impulsionadas por motores elétricos pneumáticos ou conjuntos motobombas elétricos. A idéia de se inserir a cápsula neste contexto pode ser explicada pelo fato de algumas cargas não poderem ser misturadas com o fluido transportador ou mesmo, não poderem estar em contato direto com as paredes da tubulação, devido ao desgaste provocado pelo atrito entre estas partes. Neste contexto, o transporte por meio de dutos encapsulados contribuiria desobstruindo estradas e vias urbanas, que como já foi dito, permanecem congestionadas a maior parte do tempo. Palavras-chave: Logística, transporte, dutos.

\footnotetext{
${ }^{1}$ Possui graduação em Engenharia Civil pela Fundação Percival Farquhar - Univale (1999), Mestrado em Engenharia de Transportes pelo Instituto Militar de Engenharia - IME (2003) e Doutorado em Engenharia de Transportes pela Universidade Federal do Rio de Janeiro - PET/COPPE/UFRJ (2008). Atualmente é professor Adjunto do curso de Graduação em Administração da Universidade Federal Fluminense - UFF, do Programa de Pós Graduação em Administração da UFF (Mestrado), do MBA em Logística Empresarial e Gestão da cadeia de Suprimentos da UFF e Coordenador do Curso de Gestão Pública da UFF/UNIFA.

2 Possui graduação em Matemática pelo Instituto de Matemáatica,Astronomia y Fisica ,da Universidad Nacional de Cordoba ,Argentina(1971), Master In Arts pelo Queens College da City University of New York ,USA ,(1975) e PhD em Applied Mathematics pelo Graduate Center da City University of New York ,USA ,(1978). Fez pós-doutorado na Universidade de California,campus Sao Diego,USA,1989-1990. Foi professora titular do Instituto Militar de Engenharia no Mestrado em Engenharia de Transportes( nov 1981abril de 2010). Atualmente é professora doutora na Escola de Ciências Sociais ,Mestrado em Administraçao da UNIGRANRIO.
} 


\section{Sustainable Business International Journal}

MAIO DE 2012- ISSN 1807-5908

\section{UTILIZAÇÃO DE CAPSULAS PARA O TRANSPORTE DE CARGAS POR DUTOS}

\section{INTRODUÇÃO}

O sistema rodoviário atual está chegando à saturação com o tráfego crescente no transporte de cargas e passageiros. Muitas das estradas brasileiras já se encontram permanentemente congestionadas, o que piora ainda mais a situação. A idéia de construir mais estradas deixou de ser uma prioridade na maioria das vezes por razões fiscais e ambientais.

Pesquisas estão sendo desenvolvidas a fim de se aumentar a capacidade da infra-estrutura existente e ao mesmo tempo, tem-se dado importância ao estudo de novos sistemas de transporte.

O transporte de cargas e a movimentação de pessoas têm características diferentes. Pessoas requerem flexibilidade, conveniência, e velocidade; já o transporte de cargas requer menor custo, tempo de entrega, e segurança no transporte.

Hoje, com uma combinação de vários modos de transporte de passageiros, as pessoas conseguem se locomover com facilidade. Por outro lado, transporte de cargas é feito principalmente por longo trechos de rodovias, onde os caminhões predominam. O transporte por caminhão oferece mais flexibilidade, mas não necessariamente a um custo baixo, se comparado aos trens, por exemplo.

Um outro problema incide na mistura de transporte de cargas e transporte de passageiros na mesma via, o que tem apresentado problemas referentes à segurança destes passageiros que utilizam a mesma via para deslocamentos.

No transporte por caminhões freqüentemente os motoristas têm que operar os veículos por um tempo exaustivamente longo, o que acaba comprometendo a segurança da via. A separação de transporte de cargas e de passageiros aumentaria a eficiência e segurança para ambos. 


\section{Sustainable Business International Journal}

A utilização de dutos para o transporte de alguns tipos de cargas, antes transportadas por caminhões, tem mostrado eficiência e segurança nestes deslocamentos. Este modo de transporte já é experimentado em vários países há muitos anos, e no que diz respeito a cargas líquidas ou pastosas, este meio sempre apresentou maior rendimento e segurança do que os demais concorrentes.

Uma nova idéia seria a de usar cápsulas para transportar cargas sólidas por meio de dutos, impulsionadas por motores elétricos pneumáticos ou conjuntos motobombas elétricos. A idéia de se inserir a cápsula neste contexto pode ser explicada pelo fato de algumas cargas não poderem ser misturadas com o fluido transportador ou mesmo, não poderem estar em contato direto com as paredes da tubulação, devido ao desgaste provocado pelo atrito entre estas partes.

\section{DEFINIÇÃO E VANTAGENS DO DUTO ENCAPSULADO}

O duto encapsulado é uma nova tecnologia em dutos que pode transportar cargas como carvão e outros minerais, resíduos sólidos incluindo resíduos perigosos, grãos e outros produtos agrícolas, correspondências e encomendas, e muitos outros produtos.

O duto é subterrâneo e ambientalmente amigável, seguro, confiável, energeticamente eficiente e resistente à intempéries, pois utiliza um duto subterrâneo para transporte da carga. Desta forma, não somente reduz o custo do frete, mas também o número de caminhões nas rodovias e ruas. Conseqüentemente será menor o número de congestionamentos nas rodovias e ruas, menores índices de acidentes causados por caminhões e trens de carga, e menor demanda para a infraestrutura das rodovias e estradas, com conseqüente redução no custo de manutenção da mesma. 


\section{Sustainable Business International Joumal}

\subsection{Tipos de Dutos encapsulados}

Há três tipos gerais de dutos encapsulados: Pneumátic Capsule Pipeline - PCP(duto encapsulado pneumático), Hydraulic Capsule Pipeline - HCP (duto encapsulado hidráulico), e Coal Log Pipeline - CLP(duto hidráulico de carvão).

- $\quad$ Pneumatic Capsule Pipeline (PCP): usa como veículo, cápsulas sobre rodas para levar a carga por meio de um duto cheio com ar. Este ar é usado para empurrar a cápsula dentro do duto.

Para um PCP de 3 pés de diâmetro, cada cápsula pode levar 2 toneladas de carga, viajando a aproximadamente $25 \mathrm{mph}$ sem necessidade de paradas. Elas se movem a aproximadamente a mesma velocidade média diária de um caminhão. Produtos de alto valor, como correspondências e encomendas, também podem ser transportados pelo PCP.

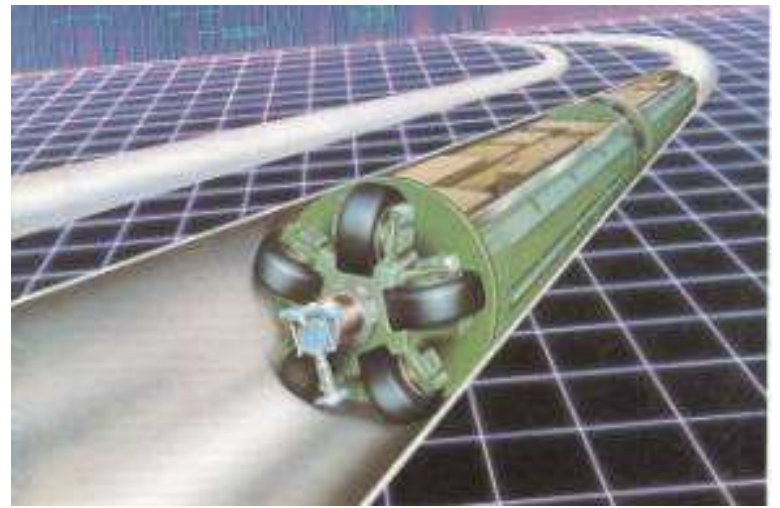

Figura1: Duto encapsulado Pneumático - PCP Fonte: Capsule Pipeline Research Center

Hydraulic Capsule Pipeline(HCP): usa cápsulas sem rodas para transportar cargas por meio de um duto cheio com água. A água é usada para flutuar e empurrar a cápsula dentro do duto.

HCP viaja de 6 a 10 pés por segundo dentro do duto, o qual o torna muito mais lento do que o PCP. No entanto, HCP pode transportar muito mais carga com o mesmo diâmetro. Ele também usa menos energia do que o PCP, o que o torna mais econômico. Conseqüentemente, o HCP é mais 


\section{\begin{tabular}{|l} 
Sustainable Business \\
|| International Journal
\end{tabular}}

MAIO DE 2012- ISSN 1807-5908

indicado para transportar materiais como grãos e outros produtos agrícolas, resíduos sólidos municipais e outros produtos de baixo valor.

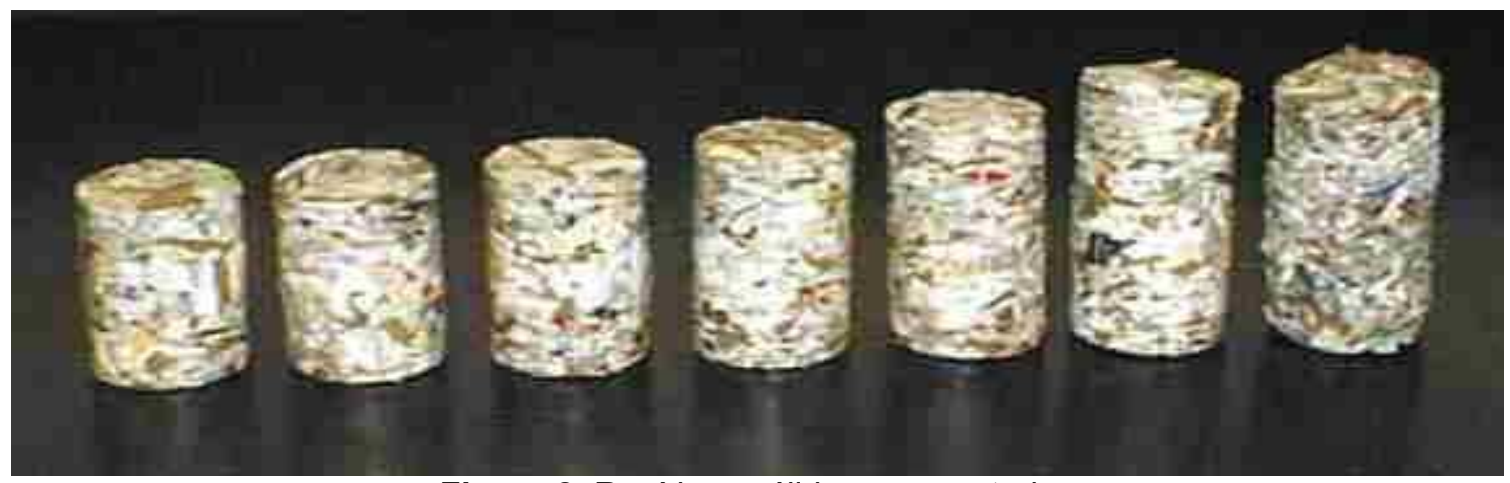

Figura 2: Resíduos sólidos compactados

Fonte: Capsule Pipeline Research Center

- Coal Log Pipeline (CLP): esta nova tecnologia é utilizada basicamente para o transporte de carvão usando dutos.

Trata se de um tipo especial de HCP em que as cápsulas são na forma de um cilindro de carvão compactado, e que podem estar em contato direto com a água e o duto. No processo do CLP, o carvão da mina é compactado em cilindros com diâmetro de 5 a $10 \%$ menor do que o duto por meio do qual o carvão será transportado. O comprimento de cada cilindro é usualmente 2 vezes o diâmetro.

Como usa água, a relação carvão/água no CLP, é de 3 a 4, dependendo do comprimento do duto. Neste meio, 1 libra de água pode transportar de 3 a 4 de carvão em um CLP. Por serem compactados em altíssimas pressões, os cilindros de carvão absorvem muito pouca água em seu trajeto e não se desmancham.

Por não precisar de receptáculo para o CLP, não há a necessidade de separar um duto para retornar cápsulas vazias, como é requer o HCP e PCP. 


\section{\begin{tabular}{|l} 
Sustainable Business \\
International Journal
\end{tabular}}

MAIO DE 2012- ISSN 1807-5908

O CLP tem o melhor custo efetivo entre os tipos de dutos encapsulados, no entanto, seu uso é limitado a carvão, alguns outros minerais, e resíduos sólidos de materiais, os quais, como o carvão podem ser compactados, serem resistentes a água, e formar cilindros resistentes .

Como nos Estados Unidos a energia elétrica é gerada fundamentalmente por fontes termoelétricas a carvão, o CLP torna-se um alternativa interessante e eficiente para o transporte deste material. É importante ressaltar que o CLP é também, muito mais eficiente energeticamente do que caminhões, para o transporte de carvão devido à grande quantidade a ser transportada e o baixo valor agregado deste material.

Figura 3: Carvão compactado e preparados para o transporte no duto encapsulado de carvão - CLP Fonte: Capsule Pipeline Research Center

\subsection{Cruzamento com rodovias, ferrovias e rios}

As tubulações cruzam rodovias, ferrovias e rios por meio de túneis subterrâneos, usando modernas tecnologias de perfuração direcional e micro-túneis. Recentes avanços da tecnologia de perfuração direcional permite a penetração de um duto, abaixo do subsolo, por mais de uma milha de distância ao longo do caminho. Isto permite que novos dutos sejam construídos cruzando rodovias, ferrovias e rios, sem perturbação(interrupção) para estas estradas e cursos d' água. 


\section{Sustainable Business International Journal}

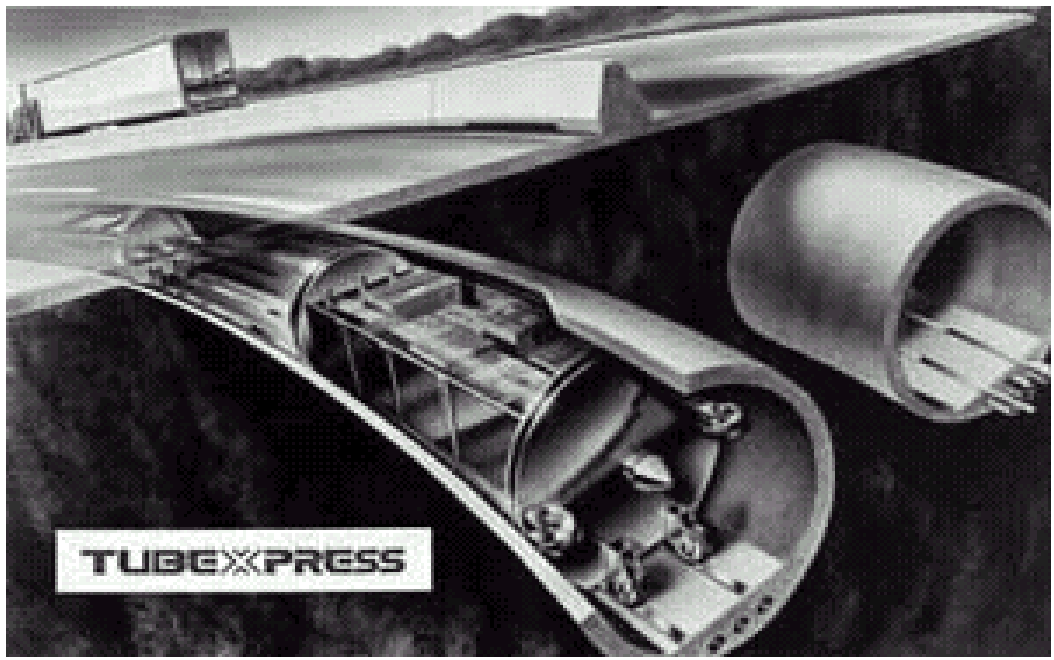

Figura 4: Segmento de duto subterrâneo ao longo da rodovia Fonte: Capsule Pipeline Research Center

\subsection{Segurança dos Dutos Encapsulados}

Segurança é a principal vantagem para o transporte subterrâneo de cargas. Como mostram as estatísticas abaixo, os dutos são, de longe, o meio de transporte de carga mais seguro.

Por instância, a cada ano nos Estados Unidos, enquanto morrem mais de 500 pessoas em acidentes ferroviários, em todos os tipos de dutos combinados morrem menos de 30 pessoas.

No caso dos dutos encapsulados este número é bem menor, uma vez que este meio não transporta cargas inflamáveis ou explosivas.

Nos Estados Unidos, dutos de todos os tipos, transportam mais carga(líquidos, gases e sólidos) a cada ano, medidos em ton-milha, do que cargas transportadas por caminhões e trens juntos. 


\section{Sustainable Business International Journal}

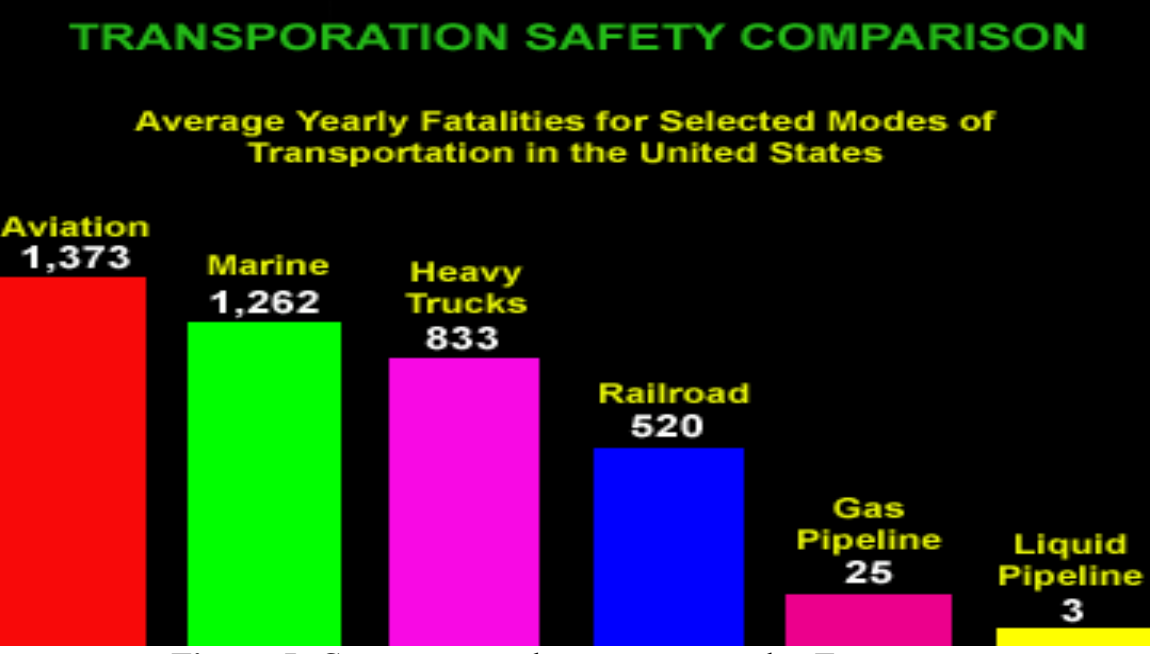

Figura 5: Comparação sobre a segurança dos Transportes Fonte: Capsule Pipeline Research Center

\section{HISTÓRICO DO TRANSPORTE CARGAS POR DUTOS ENCAPSULADOS}

O transporte de cargas por tubulações encapsuladas não é um conceito novo. Dutos de diâmetro pequenos impulsionados por bombas pneumáticas foram usados desde antes de SEGUNDA GUERRA MUNDIAL para movimentar prioritariamente documentos. Após de SEGUNDA GUERRA MUNDIAL, foram desenvolvidos dutos de grandes diâmetros para transportar pedra calcária e lixo no Japão e Rússia.

Os sistemas de dutos encapsulados para transporte de carga têm muitas características desejáveis. Dente as quais:

Os dutos são, em sua maioria, subterrâneos, o que acarreta impactos ambientais reduzidos.

Estes sistemas podem ser completamente automatizados e não interferem com movimento de pessoas.

Como o sistema é totalmente fechado, permite que sua operação ocorra sem interferências climáticas. 


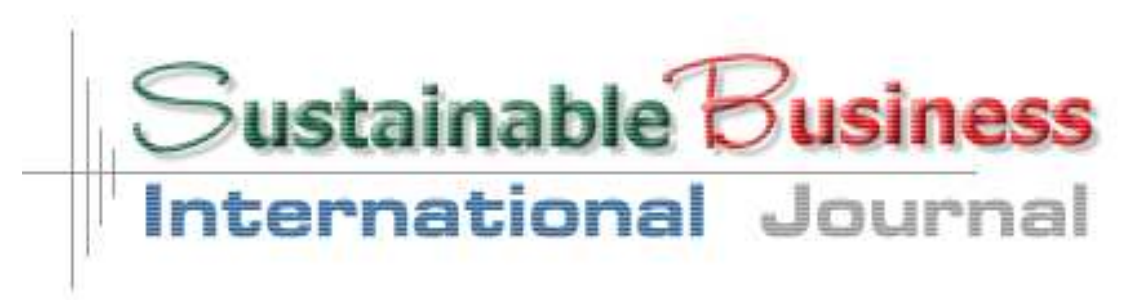

MAIO DE 2012- ISSN 1807-5908

Porém durante muito tempo os dutos encapsulados pneumáticos tiveram seu desenvolvimento travado em virtude da tecnologia das bombas pneumáticas de pequena potência, o que requeria sucessivos bombeamentos. A cada rebombeamento observava-se o problema da cápsula não poder passar pela estação de bombas como se faz com os líquidos. Deste modo sistemas ineficientes foram desenvolvidos para tentar solucionar este problema.

No entanto durante as últimas décadas, avanços tecnológicos em duas áreas tornaram possíveis as soluções para estes problemas. O primeiro foi o desenvolvimentos em motores elétricos lineares e de alta potência eliminando grande parte dos problemas encontrados nos antigos motores de baixa potência, também chamados de sopradores pneumáticos.

Outro avanço importante observado, diz respeito à construção das tubulações, com o desenvolvimento de equipamentos que aliam a rapidez com a eficiência destas construções.

\section{APLICAÇÕES HISTÓRICAS}

Alguns dutos de pequeno diâmetro foram usados para transportar telegramas e mensagens de telégrafo na Europa Ocidental e Norte da América por volta de 1850. A maioria destes sistemas saíram de uso na segunda metade do século 20. Alguns sistemas de pequenos diâmetros ainda são utilizados para a transferência de pequenos artigos por distâncias curtas.

Durante as décadas de 60 e 70, dutos de grande diâmetro foram desenvolvidos utilizando a tecnologia dos sistemas pneumáticos proporcionando maiores velocidades e maior produtividade para o transporte de cargas. Nas recentes aplicações propostas pode se citar a distribuição de bens domésticos, correio, lixo e outros. 


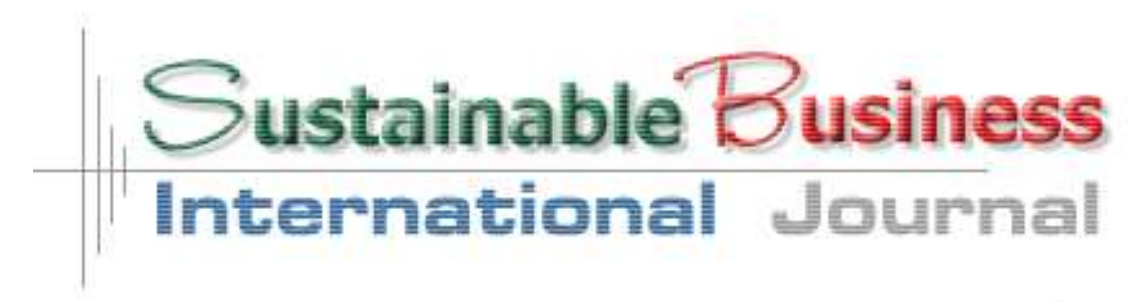

MAIO DE 2012- ISSN 1807-5908

Um dos atrativos desta nova tecnologia tem sido a consciência ambiental proporcionada por este modo de transporte. Esta tecnologia pode, também, prover uma alternativa viável à utilização do modo rodoviário e a outros modos de transporte.

Porém há uma dificuldade de financiamento e desenvolvimento de redes mais extensas. As aplicações mais viáveis atualmente encontram-se em determinados nichos de mercado como movimentos de dinheiro dentro de supermercados, ou movimento de carvão de jazidas até usinas termoelétricas.

Entretanto alguns especialistas insistem que o potencial de utilização do transporte por dutos encapsulados existe para qualquer carga a ser transportada, bastando apenas adequá-lo à carga.

A chegada do telégrafo aumentou enormemente a comunicação a distância entre cidades, fazendo com que as mensagens fossem transportadas eletronicamente em grandes velocidades. Porém, as mensagens transcritas ainda tinham que ser movidas fisicamente no interior das cidades e entre estas e outras. Deste modo dutos encapsulados pneumáticos de pequeno diâmetro serviram bem a esta tarefa.

Iniciando-se na Inglaterra, a primeira implementação prática da tecnologia de PCP estava entre os escritórios Centrais da Companhia de Telégrafo e seus escritórios à Bolsa de valores na Cidade de Londres, em 1853. O sistema carregava entre estes pontos as mensagens que tinham sido transcritas do telégrafo. A figura a seguir mostra a configuração deste primeiro PCP. 


\section{Sustainable Business International Joumal}

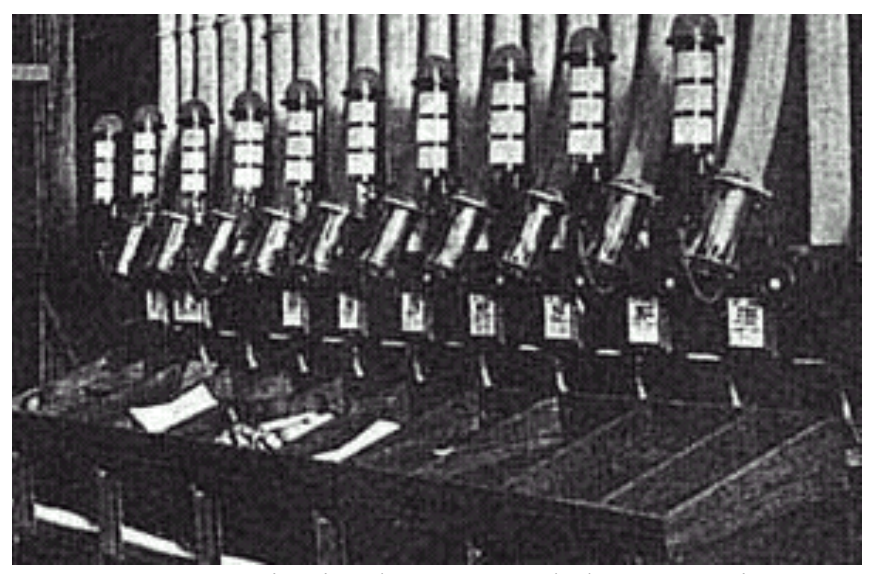

Figura 6: Primeiro duto encapsulado pneumático Fonte: Capsule Pipeline History

Mais tarde o sistema veio a interligar outros pontos, inclusive para fora da cidade de Londres. O sistema não só foi o primeiro fora de Londres, mas também a primeira instalação registrada de um sistema no qual poderiam ser enviadas mensagens em ambas as direções, usando o mesmo tubo.

Foram adotados dois tipos de sistema: House e Street Tubes. Os primeiros foram utilizados para a transmissão de mensagens entre partes diferentes do mesmo edifício, enquanto que os outros para transmissão de mensagens de telegrama dos escritórios de filial para a matriz (de onde foi telegrafado). Antes dos anos 30, foram conectados 67 escritórios de filial para a matriz por uma séries de tubos radiais. A maioria dos tubos só carregava mensagens em uma direção, sendo que alguns poucos em ambas as direções.

No seu auge, a rede de Londres fazia uso de 57 milhas de dutos. O sistema era, atraentemente usado, porque permitia manipulação de mensagens mais rapidamente do que se fossem telegrafadas de escritórios locais para matriz e também porque não havia erros de tradução. A seguir observa-se parte da rede de tubulações e as bombas pneumáticas utilizadas para a impulsão da cápsula. 


\section{Sustainable Business International Joumal}

MAIO DE 2012- ISSN 1807-5908

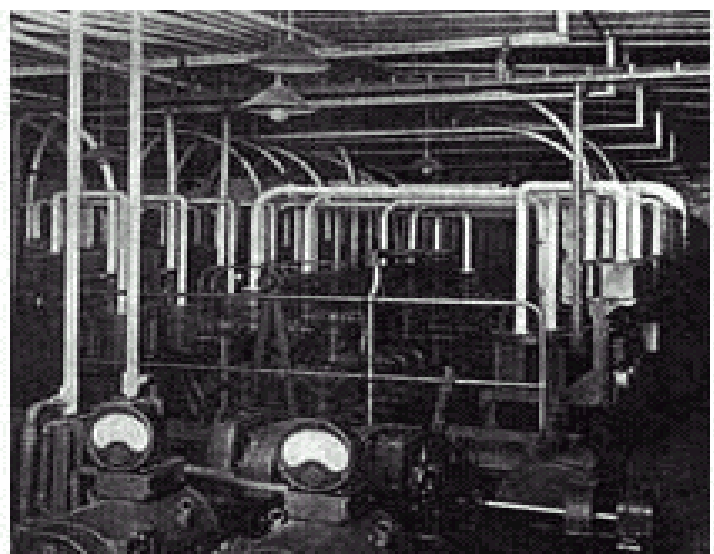

Figura 7: Rede de tubulações e Bombas Fonte: Capsule Pipeline History

A operação dos dutos encapsulados consistia na colocação das mensagens em cápsulas, cada cápsula comportava cerca de 20 a 30 mensagens. Estas cápsulas consistiam de um cilindro de aço, coberto com mangas de feltro que agiam como saias(espaçadores) dentro do tubo. Um bloco de feltro grosso era posicionado na frente da cápsula para agir como um pára-choque na sua chegada. As cápsulas eram então, despachadas em intervalos regulares e viajavam a uma velocidade de 20 MPH. O sistema de Londres permaneceu em uso até 1962, quando foi substituído pelo desenvolvimento tecnológico das redes de telefones e aparelhos de telex.

Redes semelhantes existiram em outras cidades britânicas como Liverpool, Manchester, Birmingham, Glasgow, Newcastle e Dublin.

No entanto, tais sistemas não eram comuns somente em cidades britânicas. Em 1865 foram construídos dois tubos para a troca de mensagens entre estações de Telégrafo Centrais em Berlim. No seu auge, Berlim possuiu 27 linhas de tubos totalizando $254 \mathrm{~km}$ conectando Agências Postais. Acima podem ser observadas duas das cápsulas utilizadas em Paris no seu sistema de tubulações pneumáticas, sendo o mais moderno o da esquerda. 


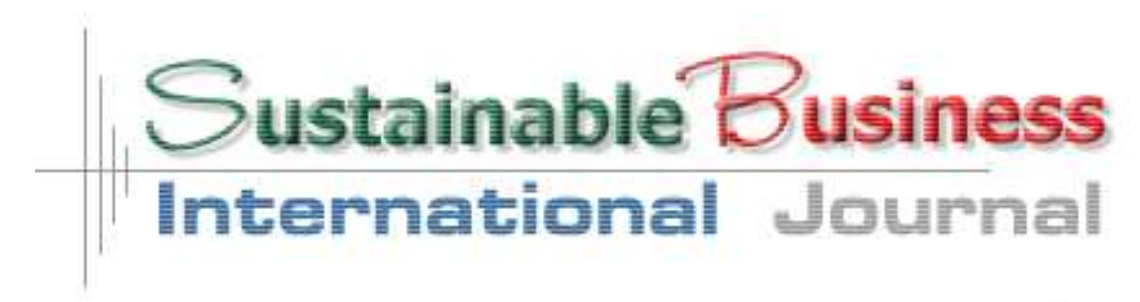

MAIO DE 2012-ISSN 1807-5908

Paris chegou a ter mais de 200 milhas de tubos pneumáticos, conhecidas como Pneumatique, ou colloquially interligando escritórios de telégrafos. O sistema foi aberto a uso público em 1879 como um sistema postal rápido e alternativo.

$\mathrm{Na}$ América, a Companhia de Telégrafo da União Ocidental construiu um sistema pneumático em Nova Iorque em 1876, utilizado para o movimento de mensagens de telégrafo. Posteriormente se espalhou para várias outras cidades Norte Americanas

\section{OUTRAS APLICAÇÕES}

No início do século 20, os PCPs parecem ter se tornado uma das formas mais populares de tecnologia para transferência dinheiro no interior de lojas, e para menores utilizações em hotéis e outras tipos de negócio.

A maioria dos principais supermercados de Reino Unido e bancos com filiais, por exemplo, usam atualmente tais sistemas para o movimento de dinheiro para locais mais seguros. Também, podem ser encontrados freqüentemente sistemas em grandes edifícios comerciais para a movimentação de papeis.

Com as grandes inovações tecnológicas sofridas por estes sistemas de transporte de papéis, o seu uso vem crescendo. Dentre estas inovações citam-se a introdução de novos materiais e sistemas de controle. A exemplo de materiais, os plásticos permitiram criar sistemas de operação menos visíveis, ou seja, escondidos ou embutidos em paredes. Proporcionaram, também, reduzidas manutenções e operações mais silenciosas. Dentre os sistemas de controle, foram desenvolvidos sistemas eletrônicos que permitem, para padrões de movimentação mais complexos, a operação com o mínimo risco de perda dos artigos que são transportados. 


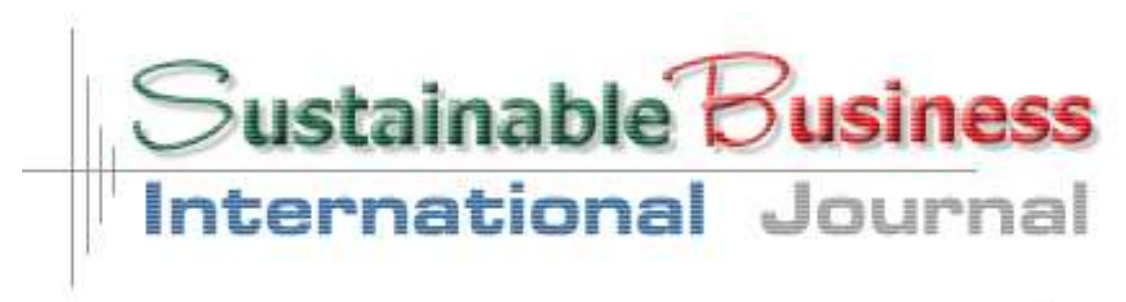

MAIO DE 2012- ISSN 1807-5908

A utilização deste sistema de transporte pode ser vista freqüentemente onde artigos físicos de pequeno porte precisam ser transferidos regularmente entre certos locais fixos. Nestes locais os sistemas substituíram eficientemente o carregamento manual realizado por uma pessoa, que geralmente utiliza cestos ou carrinhos empurrados manualmente. Como exemplo cita-se a necessidade de se transportar amostras médicas no interior de hospitais; amostras industriais para serem testadas em outros locais da industria; movimento de pequenas peças de reposição para aeronaves dentro de um aeroporto; vários documentos dentro de escritórios; e dinheiro.

\section{EFICIÊNCIA ECONÔMICA}

Certos custos econômicos geralmente não são considerados no custo monetário. Por exemplo, a poluição (atmosférica, visual, barulho, etc) causada nas estradas pelos veículos de transporte raramente é paga completamente pelo usuário de estrada.

Muitos governos estão avançando lentamente no sentido de assumir maiores responsabilidades sobre estes custos externos.

Pode-se relacionar estes custos externos, aos altos preços pagos pelos usuários pelos modos de transporte mais utilizados; que talvez não seria praticado em novas tecnologias como a aqui apresentada.

A exemplo disto pode-se ver que, nesta tecnologia, a poluição sonora é mínima, a poluição atmosférica só existe em locais onde a energia é gerada e podem ser cortadas: intrusão visual e níveis de vibração visto que em sua grande maioria, os dutos encapsulados são subterrâneos ou embutidos na estrutura dos edifícios. 


\section{Sustainable Business International Journal}

\section{UTILIZAÇÕES NO BRASIL}

No Brasil, já se observa modestamente alguma utilização pontual da tecnologia de dutos encapsulados em alguns prédios públicos e hospitais para efetuar o transporte de papéis entre os diversos andares. Também se observam algumas aplicações em rodovias pedagiadas, onde o recolhimento do dinheiro das cabines é feito por meio de cápsulas em tubulações, que se dirigem até a central de operação.

No entanto, aplicações úteis poderiam ser estudadas para o transporte de soja dos diversos centros produtores até os portos de escoamento da produção ou até os terminais ferroviários, evitando-se deste modo os intermináveis congestionamentos de rodovias na época da colheita. Modernos estudos realizados no CAPSULE PIPELINE RESEARCH CENTER, da Universidade de MissouriColumbia nos EUA, demonstram que capacidade de transporte de cada cápsula pneumática pode chegar a 2 toneladas de carga.

Outra aplicação interessante pode ser observada em outros paises para o transporte de valores entre bancos ou entre centros comerciais que necessitam movimentar expressivas quantidades de valores. No Brasil, devido à insegurança e os altos índices de assaltos a veículos de transporte de valores, conhecidos como carros-fortes, e ás perdas de vidas dos funcionários utilizados nesta atividade; as dutovias encapsuladas poderiam atenuar este problema, uma vez que não utiliza funcionários no decorrer do trajeto, a tubulação estará escondida por ser subterrânea e pelo fato de a tubulação ser totalmente monitorada na totalidade de sua linha de tubos. Deste modo, qualquer interferência ou tentativa de violação da tubulação será imediatamente detectada pelo sistema operacional deste modal.

Entre cidades que possuem intensa troca de encomendas como é o caso de Rio de Janeiro - São Paulo - Belo Horizonte, o transporte destas encomendas poderia ser realizado por meio de 


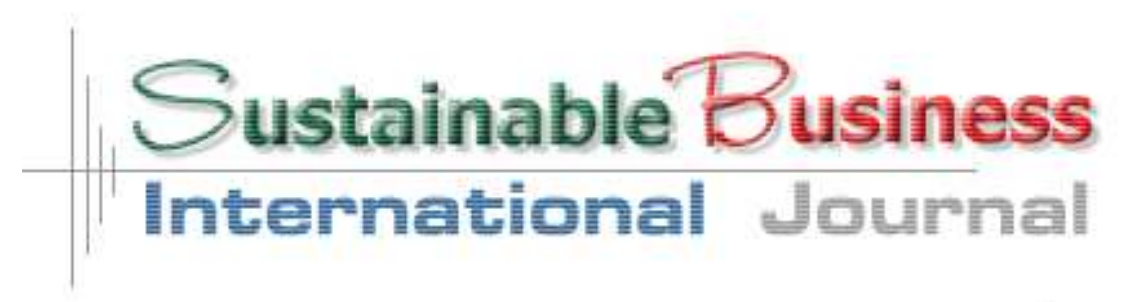

MAIO DE 2012- ISSN 1807-5908

tubulações em substituição aos caminhões ou aviões, uma vez que a agilidade seria observada pelo fato de que as cápsulas possuem menor tamanho, o que facilita o agrupamento de menores lotes de encomendas suficientes para encher a cápsula, ao contrário do caminhão ou avião, onde os lotes necessários para se atingir a carga total do veículo são muito grandes e demoram a serem agrupados fazendo com que o veículo fique esperando por várias horas.

Em parques industriais ou Campus de Universidades onde identificam uma intensa troca de documentos, as tubulações encapsuladas seriam de grande utilidade para o transporte destes. Um exemplo desta necessidade pode ser visto na Universidade Federal do Rio de Janeiro em seu campus na Ilha do Fundão, onde a entrega das diversas encomendas e papéis é realizado ineficientemente por funcionários utilizando-se de veículos motorizados. O problema incide na questão de que estes veículos estão sendo ineficientes sob o ponto de vista de "efíciência energética" e que encomendas urgentes têm que esperar até que sejam formados lotes maiores para que o veículo possa ser liberado para as entregas.

\section{CONCLUSÃo}

Do exposto, observa-se a necessidade do desenvolvimento de novas tecnologias para o transporte de cargas que possibilitem a diminuição do número de veículos nas ruas e estradas, que por sua vez já se encontram permanentemente congestionadas. Também, são necessárias tecnologias que diminuam a dependência do Brasil e do mundo dos derivados do petróleo; e ainda tecnologias que sejam menos intrusivas ao meio ambiente e que possuam operações mais seguras, sob o ponto de vista dos acidentes que envolvem pedestres e veículos. 


\section{Sustainable Business International Journal}

A tecnologia de dutos encapsulados, aqui apresentada, consegue atender a varias destas necessidades da sociedade atual, e ainda com custos reduzidos. Pois consegue operar sem a interferência dos outros modos de transporte existentes, com rapidez e segurança para a população inserida em seu contexto.

\section{BIBLIOGRAFIA}

Capsule Pipelines History, (2004) Disponível: http://www.capsu.org

Capsule Pipeline Research Center (CPRC), College of Engineering, University of Missouri-Columbia, (2003) Disponível: http://www.missouri.edu/ cprc/

Emerging Construction Technologies, (2002) Disponível: http://www.new-technologies.org/ECT/Other/pcp.htm International Freight Pipeline Society, (2003) Disponível: http://www.freightpipeline.org/news.htm Murta, A.L.S, (2003) Subsídios para o Desenvolvimento de Estudos de Impactos Ambientais para o Transporte Dutoviário, Dissertação de Mestrado, Departamento de Engenharia de Transportes, Instituto Militar de Engenharia IME.

Zhao et al, (2002) Characteristics of a Freight Pipeline Transportation System, Department of Aerospace Engineering and Mechanics, University of Minnesota, Minneapolis, MN. 